\title{
A Novel High Performance of GaN-Based HEMT with Two Channel Layers of GaN/InAlGaN
}

\author{
Reza Karami ${ }^{1}$, Masoud Sabaghi2 ${ }^{*}$, Massoud Masoumi ${ }^{1}$ \\ ${ }^{1}$ Department of Electrical Engineering, Islamshahr Branch, Islamic Azad University, Tehran, Iran \\ ${ }^{2}$ Laser and Optics Research School, Nuclear Science and Technology Research Institute (NSTRI), Tehran, Iran \\ Email: *msabaghi@aeoi.org.ir
}

How to cite this paper: Karami, R., Sabaghi, M. and Masoumi, M. (2017) A Novel High Performance of GaN-Based HEMT with Two Channel Layers of GaN/InAlGaN. World Journal of Engineering and Technology, 5, 324-332.

https://doi.org/10.4236/wjet.2017.52026

Received: January 3, 2017

Accepted: May 24, 2017

Published: May 27, 2017

Copyright (C) 2017 by authors and Scientific Research Publishing Inc. This work is licensed under the Creative Commons Attribution International License (CC BY 4.0).

http://creativecommons.org/licenses/by/4.0/

\begin{abstract}
The potential impact of GaN-based high electron mobility transistor (HEMT) with two channel layers of GaN/InAlGaN is reported. Using two-dimensional and two-carrier device simulations, we investigate the device performance focusing on the electrical potential, electron concentration, breakdown voltage and transconductance (gm). Also, the results have been compared with structure of $\mathrm{AlGaN} / \mathrm{GaN}$ HEMT. Our simulation results reveal that the proposed structure increases electron concentration, breakdown voltage and transconductance; and reduces the leakage current. Also, the mole fraction of aluminum in the InAlGaN has been optimized to create the best performing device.
\end{abstract}

\section{Keywords}

Mole Fraction, GaN/InAlGaN, Breakdown Voltage, High Electron Mobility Transistor (HEMT)

\section{Introduction}

In recent decades, $\mathrm{GaN}$ is considered an outstanding material for high frequency and high power devices due to its superior intrinsic physical properties including wide bandgap, high breakdown electric field, high electron saturation velocity and high density carriers in the form of two-dimensional electron gas with high mobility [1]-[8]. Wide bandgap semiconductor power devices offer great performance improvements and can work in harsh environments where silicon power devices cannot function. One of the main advantages of III-nitride materials such as gallium nitride is the ability to form a heterojunction with a ternary alloy made from another III-nitride semiconductor material such as aluminium gallium nitride [9]-[14]. The high electric breakdown field of GaN is a result of the wide bandgap of $3.44 \mathrm{eV}$ at room temperature of the material and enables 
the application of high supply voltages on GaN-based devices, which is one of the two requirements for high power device performance. Therefore, these material properties clearly indicate why $\mathrm{GaN}$ is a serious candidate for next generation microwave high power and high temperature applications [7] [11] [12] [13] [14].

In recent years, GaN-based high electron mobility transistor (HEMT) has attracted considerable attentions and shown excellent performance in high power and high frequency microwave applications because of wide band-gap, superior carrier saturation velocity, large breakdown field strength and strong spontaneous and piezoelectric polarization [1] [2] [15] [16] [17] [18]. Due to the its unique characteristic and excellent performance in high power operations, Al$\mathrm{GaN} / \mathrm{GaN}$ HEMTs are emerging as the promising candidates for next generation radio frequency power amplifiers [18]-[27].

In this paper, the potential impact of GaN-based HEMT with two channel layers of $\mathrm{GaN} / \mathrm{InAlGaN}$ is studied using a two dimensional device simulator. The unique features of the HEMT with two channel layers of GaN/ InAlGaN are explored and compared with those of AlGaN/GaN and AlGaN/InGaN HEMTs in terms of the drain current, electrical potential, breakdown voltage and transconductance (gm).

In the next section, the proposed structure dimensions and the physical models used in the 2-D simulation are described in detail. In the third section, we explain how the presence of the two channel layers of GaN/InAlGaN will enhance performance of GaN-based HEMT. Also, in this section, the effect of these layers on the electrical potential, electron concentration, breakdown voltage and transconductance are studied and compared with that in structure of $\mathrm{AlGaN} / \mathrm{GaN}$ HEMT in details.

\section{Device Structure}

Figures 1(a)-(c) show the schematic cross section of AlGaN/GaN, AlGaN/InGaN and GaN-based HEMT with two channel layers of GaN/InAlGaN, respectively. The dimensions of the structures are as follows: gate length of $1 \mu \mathrm{m}$, gate-drain spacing of $1 \mu \mathrm{m}$, gate-source spacing of $1 \mu \mathrm{m}$. Barrier layer and two channel thicknesses of GaN/InAlGaN are $3 \mathrm{~nm}, 5 \mathrm{~nm}$ and $3 \mathrm{~mm}$, respectively. The spacer layer is an n-type heavily doped $\mathrm{Al}_{0.3} \mathrm{Ga}_{0.7} \mathrm{~N}$ thicknesses of $3 \mathrm{~nm}$. Also, the p-layer in the barrier is a p-type heavily doped $\mathrm{Al}_{0.3} \mathrm{Ga}_{0.7} \mathrm{~N}$ with doping concentration of $2 \mathrm{e}^{18}$. The work function of gate is $5.1 \mathrm{eV}$ for the gate schottky contact. The devices are simulated using two dimensional SILVACO software [28]. The several models are activated in order to achieve more realistic results in simulations that including the SRH, Conmob, Fldmob and Fermi Dirac models for Shockley-Read-Hall recombination, standard concentration dependent mobility, parallel electric field-dependent mobility and statistics [28].

\section{Results and Discussion}

At first, we optimized the mole fraction of aluminum in the InAlGaN to create 


\begin{tabular}{|c|c|c|c|c|}
\hline $\mathrm{F} \leftrightarrows 1 \mu \mathrm{m}$ & \multicolumn{3}{|c|}{$\stackrel{1 \mu \mathrm{m}}{\rightleftarrows}$} & \multirow{2}{*}{$\frac{1 \mu \mathrm{m}}{\mathrm{D}}$} \\
\hline$=\mathrm{S}$ & $\mathrm{SiO}_{2}$ & G & $\mathrm{SiO}_{2}$ & \\
\hline \multicolumn{5}{|c|}{$2 \mathrm{~nm}-\mathrm{A} 10.3 \mathrm{Ga} 0.7 \mathrm{~N}$} \\
\hline \multicolumn{5}{|c|}{$15 \mathrm{~nm}-\mathrm{A} 10.3 \mathrm{Ga} 0.7 \mathrm{~N}(\mathrm{n}=2 \mathrm{e} 18)$} \\
\hline \multicolumn{5}{|c|}{$3 \mathrm{~nm}-\mathrm{A} 10.3 \mathrm{Ga} 0.7 \mathrm{~N}$} \\
\hline \multicolumn{5}{|c|}{$5 \mathrm{~nm}-\mathrm{GaN}$} \\
\hline \multicolumn{5}{|c|}{$2.5 \mu \mathrm{m}-\mathrm{GaN}$} \\
\hline Sapph & & & & \\
\hline
\end{tabular}

(a)

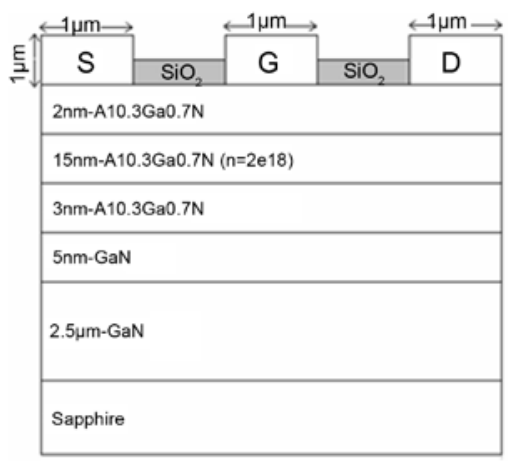

(b)

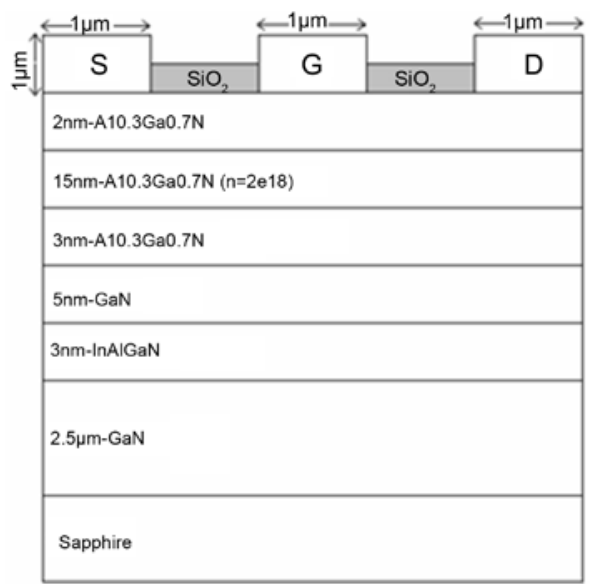

(c)

Figure 1. Schematic cross section of (a) $\mathrm{AlGaN} / \mathrm{GaN}$; (b) $\mathrm{AlGaN} / \mathrm{InGaN}$ and (c) GaN-based HEMT with two channel layers of GaN/InAlGaN.

the best performing device. Table 1 show the different structure parameters of InAlGaN layer with various mole fraction including polarization charge, band gap, conduction band and critical electric field. As seen, the polarization charge increases with lower mole fraction of aluminum that causes higher electron consternation. However, the higher mole fraction of aluminum causes higher critical electric field. Therefore, the best of mole fraction of aluminum is value that has the most polarization charge and the critical electric field greater than critical electric field of GaN. Figure 2 and Figure 3 show the potential and electron concentration in the channel below at gate voltage of zero, respectively. The concentration is normalized to $N_{o}=1 \times 10^{18} \mathrm{~cm}^{-3}$. Also, the energy axis in this figure is normalized to $25 \mathrm{meV}$. As can be seen from these figures, the structure with $\operatorname{In}_{0.15} \mathrm{Al}_{0.2} \mathrm{GaN}$ layer has higher potential barrier and electron concentration than the other two structures. Therefore, structure with $\operatorname{In}_{0.15} \mathrm{Al}_{0.2} \mathrm{GaN}$ layer has higher transconductance as can be shown in Figure 4.

Figure 5 and Figure 6 show the comparison of electron concentration and transconductane values between GaN-based HEMT with two channel layers of GaN/InAlGaN and of AlGaN/GaN HEMT. It is evident that GaN-based HEMT with two channel layers of $\mathrm{GaN} / \mathrm{InAlGaN}$ has a high potential barrier before the channel. It causes that leakage current decreases. On the other hand, Figure 5 


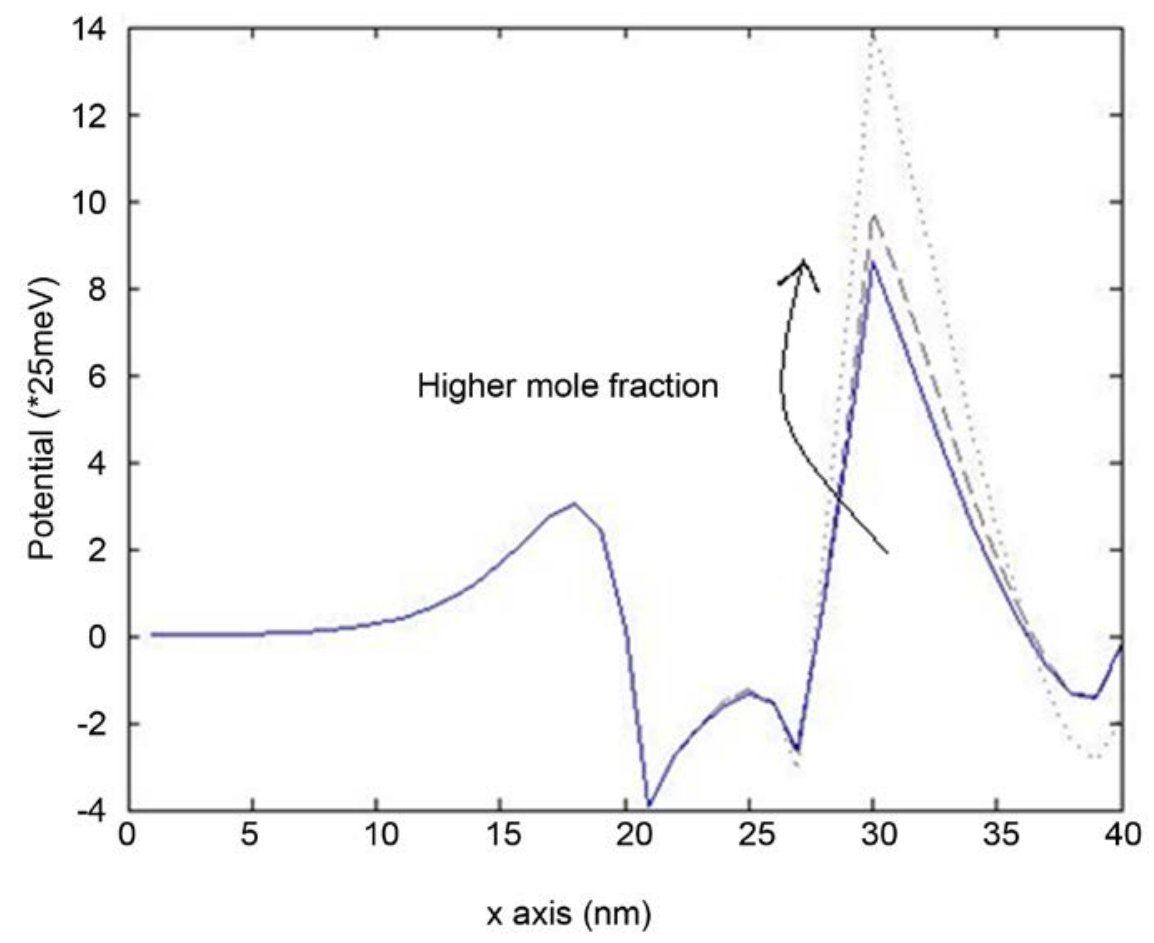

Figure 2. The Potential of GaN-based HEMT with two channel layers of GaN/InAlGaN in the channel below at gate voltage of zero.

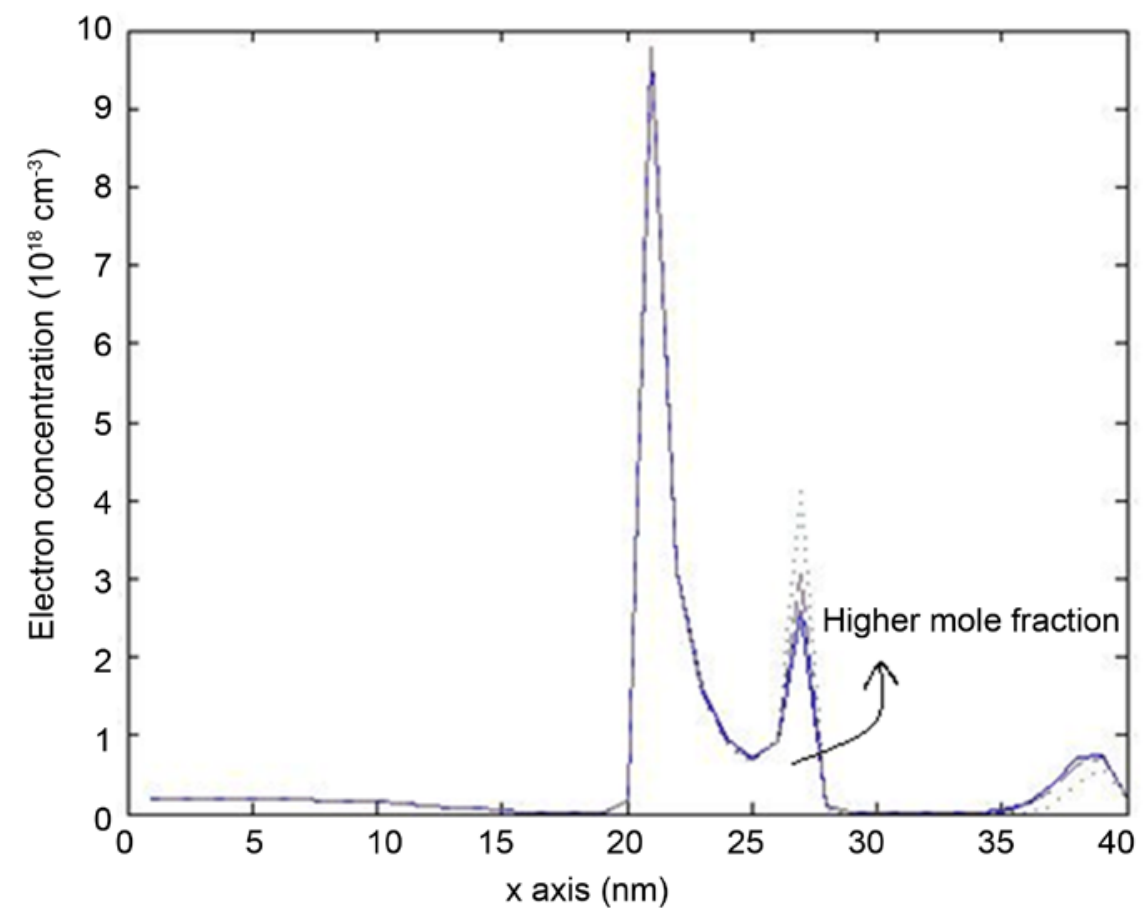

Figure 3. The Electron concentration of GaN-based HEMT with two channel layers of $\mathrm{GaN} / \mathrm{InAlGaN}$ in the channel below at gate voltage of zero.

shows that electron concentration for GaN/InAlGaN structure, which have two channel layers, is higher than the AlGaN/GaN HEMT. The GaN/InAlGaN structure have two channel layers which causes more total electron mobility in 
Table 1. The structure parameters of InAlGaN layer with various mole fraction including polarization charge, band gap, conduction band and critical electric field.

\begin{tabular}{ccccc}
\hline Material & Polarization Charge & Band Gap(ev) & Conduction Band(ev) & Ecrit(Mv/Cm) \\
\hline $\mathrm{In}_{0.1} \mathrm{GaN}$ & $1.25 \mathrm{E} 26$ & 3.026 & -0.248 & 1.75 \\
$\mathrm{In}_{0.1} \mathrm{Al}_{0.13} \mathrm{GaN}$ & $8.09 \mathrm{E} 25$ & 3.3 & -0.074 & 2.01 \\
$\mathrm{In}_{0.1} \mathrm{Al}_{0.15} \mathrm{GaN}$ & $7.35 \mathrm{E} 25$ & 3.347 & -0.046 & 2.016 \\
$\mathrm{In}_{0.15} \mathrm{Al}_{0.2} \mathrm{GaN}$ & $1.09 \mathrm{E} 26$ & 3.26 & -0.099 & 2.06 \\
\hline
\end{tabular}

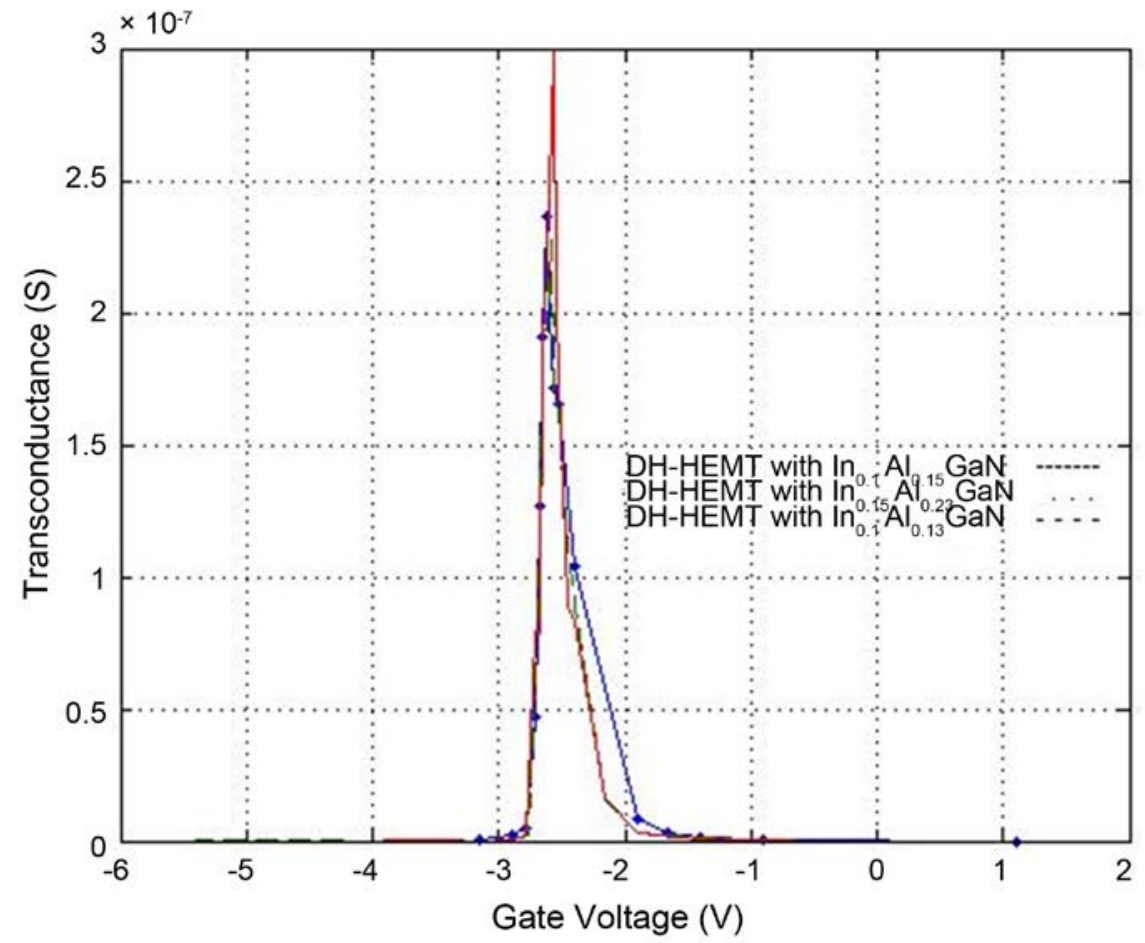

Figure 4. The Comparison of Transconductane values of GaN/InAlGaN HEMT with different mole fraction of aluminum.

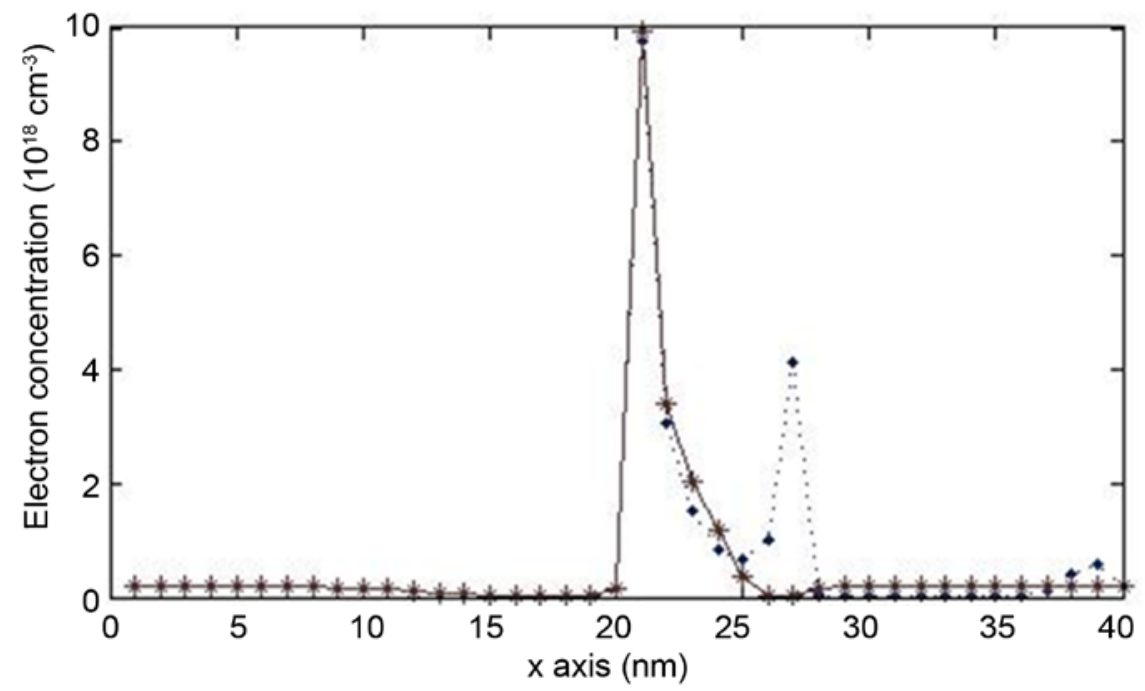

Figure 5. The comparison of electron concentration values between GaN-based HEMT with two channel layers of GaN/InAlGaN and of AlGaN/GaN HEMT. 
the two channels and as a result more transconductance, as can be seen in Figure 6.

Generally, the breakdown in HEMTs can occur because of different effects including impact ionization, tunneling or surface states that it is important to find the dominant effect in order to control the breakdown of HEMTs. The off-state breakdown occurs at a drain-source voltage when the applied gate voltage causes that channel is pinched off [10] [29]. In this way, the maximum electric field occurs at the edge of gate in drain side and then the impact ionization is dominant effect of the breakdown. Figure 7 shows the electric field in $\mathrm{x}$ axis of GaN-based HEMT with two channel layers of GaN/InAlGaN. Since the InAl$\mathrm{GaN}$ material has higher critical field in comparing with that of AlGaN/GaN, the breakdown voltage of GaN-based HEMT with two channel layers of GaN/In$\mathrm{AlGaN}$ is larger. As can be seen from Figure 7, the electric field has critical in drain voltage of $-130 \mathrm{~V}$ compared with $90 \mathrm{~V}$ of the conventional HEMT and structure has in off-state breakdown.

\section{Conclusion}

To improve the electrical potential, electron concentration, breakdown voltage and transconductance, we have proposed a novel GaN-based HEMT that has two channel layers of GaN/InAlGaN. This new structure increases electron concentration, breakdown voltage and transconductance; and reduces the leakage current. The breakdown voltage of $130 \mathrm{~V}$ is obtained for the GaN/InAlGaN com-

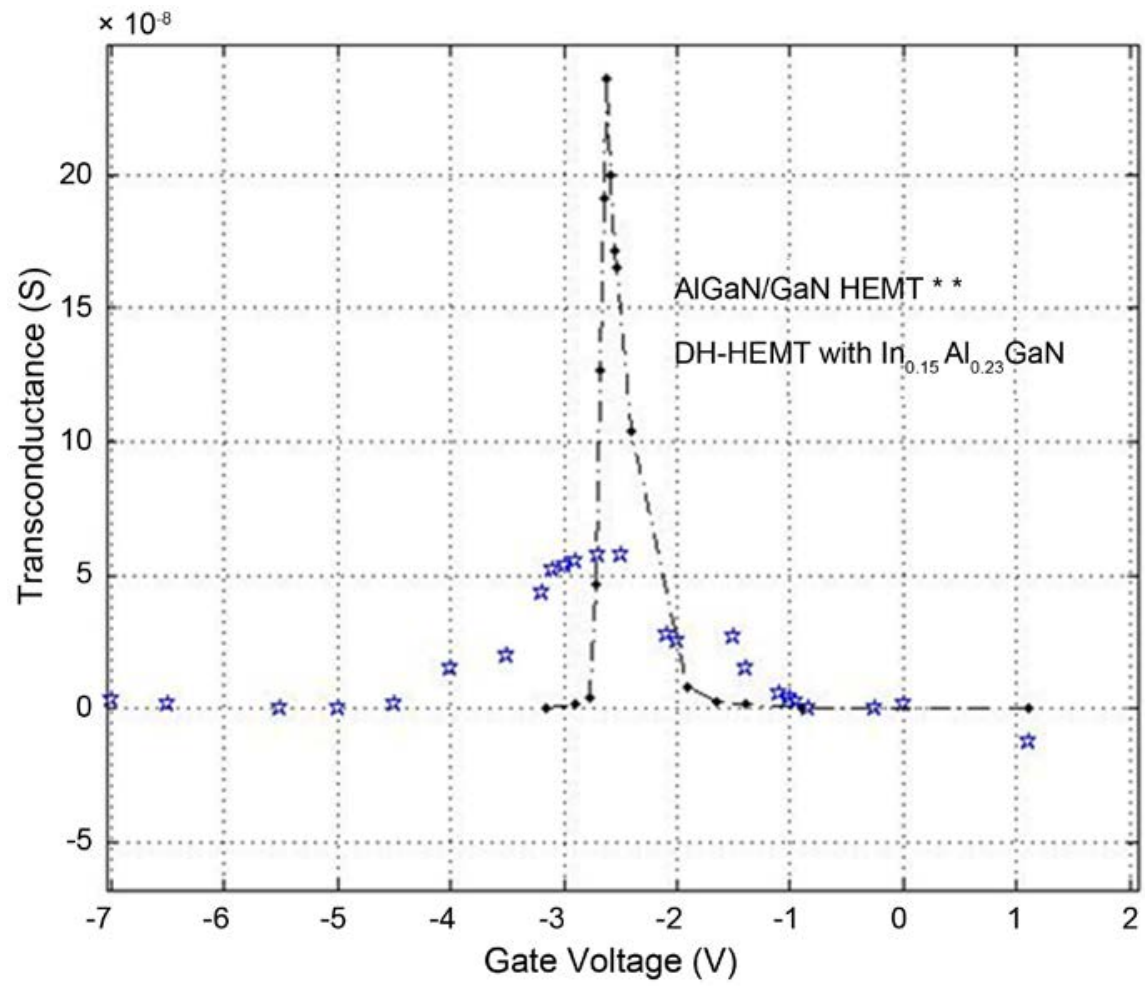

Figure 6. The comparison of transconductane values between GaN-based HEMT with two channel layers of GaN/InAlGaN and of AlGaN/GaN HEMT. 


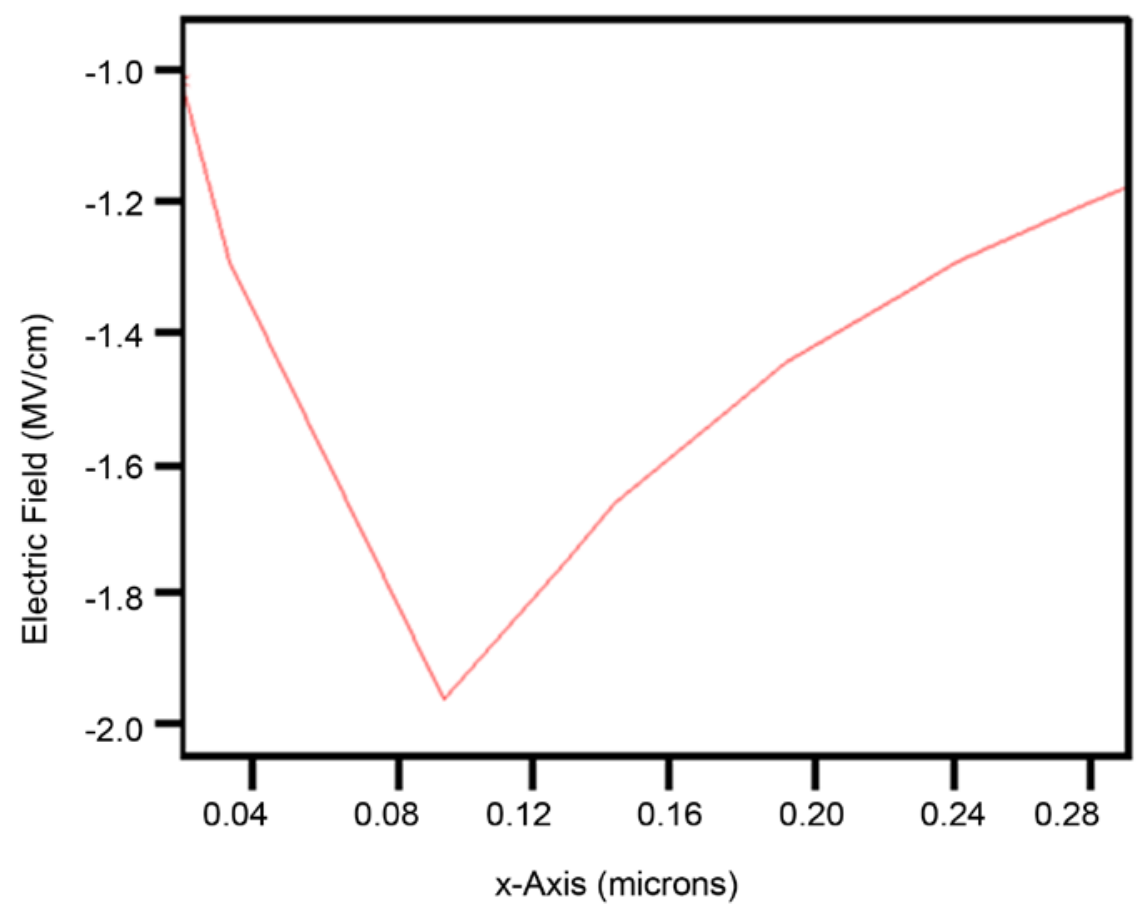

Figure 7. The Electric Field in $\mathrm{x}$ Axis of GaN-based HEMT with two channel layers of GaN/InAlGaN.

pared with $90 \mathrm{~V}$ of the conventional HEMT. Also, the mole fraction of aluminum in the InAlGaN has been optimized to create the best performing device.

\section{References}

[1] Siert, P. and Krimmel, E, (2004) Silicon: Evolution and Future of a Technology. Springer, Berlin.

[2] Adler, M., Owyang K.B., Baliga, B.J. and Kokosa, R. (1984) The Evolution of Power Device Technology. IEEE Transactions on Electron Devices, 31, 1570-1591. https://doi.org/10.1109/T-ED.1984.21754

[3] Yole Développement (2014) Wide Band Gap Power Electronics: A Path toward $\mathrm{CO}_{2}$ Emission Decrease. Technical Report, Yole Développement, Villeurbanne.

[4] Ozpineci, B., Tolbert, L.M.S., Islam, K. and Chinthavali, M. (2003) Comparison of Wide Bandgap Semiconductors for Power Applications. European Conference on Power Electronics and Applications, Toulouse, 2-4 September 2003, 2-4.

[5] Mishra, U., Parikh, P. and Wu, Y.F. (2002) AlGaN/GaN HEMTs-An Overview of Device Operation and Applications. Proceedings of the IEEE, 90, 1022-1031. https://doi.org/10.1109/JPROC.2002.1021567

[6] Kemerley, R., Wallace, H. and Yoder, M. (2002) Impact of Wide Bandgap Microwave Devices on DoD Systems. Proceedings of the IEEE, 90, 1059-1064. https://doi.org/10.1109/JPROC.2002.1021570

[7] Quay, R. (2008) Gallium Nitride Electronics. Springer, Heidelberg.

[8] Marino, F.A., Faralli, N., Ferry, D.K., Goodnick, S.M. and Saraniti, M. (2009) Figures of Merit in High-Frequency and High-Power GaN HEMTs. Journal of Physics: Conference Series, 193, Article ID: 012040. https://doi.org/10.1088/1742-6596/193/1/012040

[9] Baliga, B.J. (1989) Power Semiconductor Device Figure of Merit for High-Fre- 
quency Applications. IEEE Electron Device Letters, 10, 455-457. https://doi.org/10.1109/55.43098

[10] Shur, M. and Davis, R. (2004) GaN-Based Materials and Devices: Growth, Fabrication, Characterization and Performance. World Scientific, Singapore.

https://doi.org/10.1142/5539

[11] Rossberg, M., Vogler, B. and Herzer, R. (2007) 600V SOI Gate Driver IC with Advanced Level Shifter Concepts for Medium and High Power Applications. European Conference on Power Electronics and Applications, Denmark, 2-5 September 2007, $1-8$.

[12] Baliga, B.J. (2008) Fundamentals of Power Semiconductor Devices. Springer, New York. https://doi.org/10.1007/978-0-387-47314-7

[13] Kaiser, S., Jakob, M., Zweck, J., Gebhardt, W., Ambacher, O., Dimitrov, R., Schremer, A., Smart, J. and Shealy, J. (2000) Structural Properties of AlGaN/GaN Heterostructures on $\mathrm{Si}(111)$ Substrates Suitable for High-Electron Mobility Transistors. Journal of Vacuum Science Technology B: Microelectronics and Nanometer Structures, 18, 733-740. https://doi.org/10.1116/1.591268

[14] Tripathy, S., Lin, V.K.X., Dolmanan, S.B., Tan, J.P.Y., Kajen, R.S., Bera, L.K., Teo, S.L., Kumar, M.K., Arulkumaran, S., Ng, G.I., Vicknesh, S., Todd, S., Wang, W.Z., Lo, G.Q., Li, H., Lee, D. and Han, S. (2012) AlGaN/GaN Two-Dimensional Electron Gas Heterostructures on 200mm Diameter Si(111). Applied Physics Letters, 101, Article ID: 082110. https://doi.org/10.1063/1.4746751

[15] Zhang, Y., Sun, M., Joglekar, S.J., Fujishima, T. and Palacios, T. (2013) Threshold Voltage Control by Gate Oxide Thickness in Fluorinated GaN Metal-Oxide-Semiconductor High-Electron-Mobility Transistors. Applied Physics Letters, 103, Article: 082917.

[16] Yole Developpement (2014) GaN Technologies for Power Electronic Applications: Industry and Market Status \& Forecasts. Technical Report, Yole Développement, Villeurbanne.

[17] Scott, M., Li, J. and Wang, J. (2013) Applications of Gallium Nitride in Power Electronics. IEEE Power and Energy Conference at Illinois (PECI), Illinois, 23-24 February $2013,1-7$.

[18] Millan, J., Godignon, P., Perpina, X., Perez-Tomas, A. and Rebollo, J. (2014) A Survey of Wide Bandgap Power Semiconductor Devices. IEEE Transactions on Power Electronics, 29, 2155-2163. https://doi.org/10.1109/TPEL.2013.2268900

[19] Kachi, T., Kikuta, D. and Uesugi, T. (2012) GaN Power Device and Reliability for Automotive Applications. IEEE International Reliability Physics Symposium (IRPS), Anaheim, 15-19 April 2012, 3D.1.1-3D.1.4.

https://doi.org/10.1109/irps.2012.6241815

[20] Marjani, S. (2013) Optimization of an InGaAsP Vertical-Cavity Surface-Emitting Diode Lasers for High-Power Single-Mode Operation in $1550 \mathrm{Nm}$ Optical-Fibre Communication Systems. Asian Journal of Chemistry, 25, 4150-4152.

[21] Madadi, R., Faez R. and Marjani, S. (2013) Influence of Physical Parameters on Microwave Noise Characteristics of AlGaN/GaN/In ${ }_{0.1} \mathrm{Ga}_{0.9} \mathrm{~N} / \mathrm{GaN}$ Double-Heterojunction HEMTs. The 21 st Iranian Conference on Electrical Engineering (ICEE), Mashhad, 14-16 May 2013, 1-6.

[22] Oka, T., Ueno, Y., Ina, T. and Hasegawa, K. (2014) Vertical GaN-based Trench Metal Oxide Semiconductor Field-Effect Transistors on A Free-Standing GaN Substrate with Blocking Voltage of $1.6 \mathrm{kV}$. Applied Physics Express, 7, Article ID: 021002. https://doi.org/10.7567/APEX.7.021002 
[23] Majdabadi, A., Marjani S. and Sabaghi, M. (2014) Threshold Characteristics Enhancement of a Single Mode $1.55 \mu \mathrm{m}$ InGaAsP Photonic Crystal VCSEL for Optical Communication Systems. Optics and Photonics Journal, 4, 296-303. https://doi.org/10.4236/opj.2014.410029

[24] Brown, J.R., Macfarlane, D., Al-Khalidi, A., Li, X., Ternent, G., Zhou, H., Thayne I. and Wasige, E. (2014) A Sub-Critical Barrier Thickness Normally-Off AlGaN/GaN MOS HEMT. IEEE Electron Device Letters, 35, 906-908. https://doi.org/10.1109/LED.2014.2334394

[25] Madadi, R., Marjani, S., Faez, R. and Hosseini, S.E. (2014) The Effect of Adding InGaN Interlayer on AlGaN/GaN Double-Channel HEMT for Noise Improvement. Journal of Electrical Systems and Signals, 2, 15-20.

[26] Madadi, R., Faez, R. and Marjani, S. (2014) Dc and Microwave Noise Characteristics of AlGaN/GaN HEMT with AlN and InGaN Interlayers. The 22nd Iranian Conference on Electrical Engineering (ICEE), Tehran, 20-22 May 2014, 480-483. https://doi.org/10.1109/iraniancee.2014.6999589

[27] Brown, R., Al-Khalidi, A., Macfarlane, D., Taking, S., Ternent, G., Thayne, I. and Wasige, E. (2014) Novel High Performance AlGaN/GaN-based Enhancement-Mode Metal-Oxide Semiconductor High Electron Mobility Transistor. Physica Status Solidi, 11, 844-847. https://doi.org/10.1002/pssc.201300179

[28] Silvaco International (2015) ATLAS User's Manual: Device Simulation Software. Silvaco International, Santa Clara.

[29] Meneghesso, G., Massari, G., Buttari, D., Bortoletto, A., Maretto, M. and Zanoni, E. (1999) DC and Pulsed Measurements of on-State Breakdown Voltage in GaAs MESFETs and InP-Based HEMTs. Microelectronic Reliability, 39, 1759-1763. https://doi.org/10.1016/S0026-2714(99)00182-1

\section{Submit or recommend next manuscript to SCIRP and we will provide best} service for you:

Accepting pre-submission inquiries through Email, Facebook, LinkedIn, Twitter, etc. A wide selection of journals (inclusive of 9 subjects, more than 200 journals)

Providing 24-hour high-quality service

User-friendly online submission system

Fair and swift peer-review system

Efficient typesetting and proofreading procedure

Display of the result of downloads and visits, as well as the number of cited articles

Maximum dissemination of your research work

Submit your manuscript at: http://papersubmission.scirp.org/

Or contactwjet@scirp.org 